

\section{Sumário}

Editorial

Mariela Morales Antoniazzi, Flávia Piovesan e Patrícia Perrone Campos Mello

I. Parte Geral

1. Constitucionalismo transformador: IUS Constitutionale Commune Na

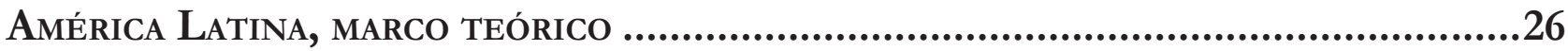

CONSTITUCIONALISMO TRANSFORMADOR INTERNACIONAL NA AMÉRICA LATINA......................28 Armin von Bogdandy e René Urueña

INTERDEPENDÊNCIA E INDIVISIBILIDADE DOS DIREITOS HUMANOS: UM NOVO OLHAR PARA A PANDEMIA DE Covid-19. .75

Flávia Piovesan e Mariela Morales Antoniazzi

DirEITOS HUMANOS EM TEMPOS DE EMERGÊNCIA: UMA PERSPECTIVA INTERAMERICANA COM especial foco na Defesa do Estado de Direito .95

Christine Binder

Monitoramento, PERSUASÃo E PROMOÇão do diálogo: QUAL O PAPEL DOS ORGANISMOS SUPRANACIONAIS DE DIREITOS HUMANOS NA IMPLEMENTAÇÃO DE DECISÕES INDIVIDUAIS?

Clara Sandoval, Philip Leach e Rachel Murray

REPENSANDO AS DERROGaÇÕES AOS TRATAdOS DE DiREITOS HUMANOS 142 Laurence R. Helfer

\section{ResiliÊNCIA DEMOCRÁtica: CoNTRIBUiçÕes do CONSTITUCIONALISMO}

TRANSFORMADOR CONTRA O RETROCESSO

A COMISSÃo INTERAMERICANA DE DiREITOS HUMANOS COMO WATCHDOG DEMOCRÁTICO: DESENVOLVENDO UM SISTEMA DE ALERTA PRECOCE CONTRA ATAQUES SISTÊMICOS...................169 Patrícia Perrone Campos Mello, Danuta Rafaela de Souza Calazans e Renata Helena Souza Batista de Azevedo Rudolf

Erosão democrática e a Corte InTeramericana de direitos humanos: o caso VENEZUELANO 196

Roberto Dias e Thomaz Fiterman Tedesco

ParticipaÇão política no Constitucionalismo latino-americano: uma ComparaÇão com o MODELO BRASILEIRO. 226 Júlio Grostein e Yuri Novais Magalhães 


\section{REFUNDAÇÃo DEMOCRÁtICA CONTRIBUIÇÕES DO CONSTITUCIONALISMO}

TRANSFORMADOR A UMA NOVA ORDEM CONSTITUCIONAL

LOS DERECHOS SOCIALES Y EL CONSTITUCIONALISMO TRANSFORMAdOR EN CHILE .251

Gonzalo Aguilar Cavallo

La aplicación del Derecho internacional de los derechos humanos en Chile: DIAGNÓSTICOS Y PROPUESTAS PARA UNA NUEVA CONSTITUCIÓN TRANSFORMADORA .275

Pietro Sferrazza Taibi, Daniela Méndez Royo e Eduardo Bofill Chávez

Diálogo Judicial no Ius COMMUNE LATINO-AMERICANO: COERÊNCIA, COESÃo E CONFORMAÇão CONSTITUCIONAL 314

Paulo Brasil Menezes

4. Diálogo ENTRE ORDENS INTERNACIONAIS E NACIONAIS: O CONSTITUCIONALISMO TRANSFORMADOR NA AMÉRICA LATINA

DIÁLOGO, INTERAMERICANIZACIÓN E IMPULSO TRANSFORMADOR: LOS FORMANTES TEÓRICOS DEL Ius Constitutionale Commune en América Latina ...............................................338 Mario Molina Hernández

O controle de convencionalidade pela Corte Interamericana de Direitos Humanos 364

Danilo Garnica Simini e José Blanes Sala

Controle legislativo DE CONVENCIONALIDADE DAS LEIS: A OPORTUNIDADE DE CONSTRUÇÃo do Ius Constitutionale Commune latino-americano pela Comissão de Constituição, Justiça e Cidadania da Câmara dos Deputados. .384

Ana Carolina Barbosa Pereira

A progressiva superaÇão da regulação do crime de desacato na América Latina: DIÁLOGOS ENTRE O DOMÉSTICO E O INTERNACIONAL .426 Luiz Guilherme Arcaro Conci e Melina Girardi Fachin

A interpretação do Sistema Interamericano de Direitos Humanos acerca da LIBERDADE DE EXPRESSÃo E A ADEQUAÇÃo MATERIAL DA LEI N. ${ }^{\circ} 13.834 / 2019$ 457 Elder Maia Goltzman e Mônica Teresa Costa Sousa

CAMINHOS LATINO-AMERICANOS A INSPIRAR A JURISDIÇÃo CONSTITUCIONAL BRASILEIRA NO DIÁLOGO MULTINÍVEL DO CONSTITUCIONALISMO REGIONAL TRANSFORMADOR .476 Rafael Osvaldo Machado Moura e Claudia Maria Barbosa

IUS CONSTITUTIONALE COMMUNE E DIREITO DE FAMÍlIA: UMA ANÁLISE HERMENÊUTICA DA jurisprudência da Corte Interamericana de Direitos Humanos e do Supremo Tribunal 
FEDERAL NA MATÉria

Felipe Frank e Lucas Miguel Gonçalves Bugalski

JusticiabilidAde DiRETA dos DiREITOS SOCIAIS NA CORTE INTERAMERICANA DE DIREITOS HUMANOS: MAIS UMA PEÇA NO QUEBRA-CABEÇA DO IUS CONSTITUTIONALE COMMUNE LATINOAMERICANO?.

Wellington Boigues Corbalan Tebar e Fernando de Brito Alves

5. DiÁlogo ENTRE ORDENS INTERNACIONAIS: O CONSTITUCIONALISMO TRANSFORMADOR ENTRE REGIÕES.

LA JURISPRUDENCIA EN EL DERECHO INTERNACIONAL GENERAL Y EL VALOR E IMPACTO DE LA jurisprudencia de la Corte Interamericana de Derechos Humanos y el Tribunal Europeo de Derechos Humanos..................................................................5545 Humberto Nogueira Alcalá

Diálogos À deriva: o Caso Lucien IKIli Rashidi c. República Unida da Tanzânia e outros e o esvaziamento da Corte Africana...........................................................568

Marcus Vinicius Porcaro Nunes Schubert e Catarina Mendes Valente Ramos

II. Parte especial

6. Povos indígenas E TRANSFORMAÇão

Hermenéuticas del derecho humano a la identidad CUltural EN La JURisprudencia INTERAMERICANA, UN ANÁLISIS COMPARADO A LA LUZ DEL ICCAL. .593 Juan Jorge Faundes e Paloma Buendía Molina

Ius Constitutionale Commune e O DiReito INdígena bRasileiro: os IMPaCtos da DeCisÃo do caso Povo Xukuru versus Brasil na jurisprudênCia e na administração pública NACIONAL

Flavianne Fernanda Bitencourt Nóbrega, Maria Eduarda Matos de Paffer e Anne Heloise Barbosa do Nascimento

Os PRECEDENTES dA CORTE INTERAMERICANA DE DIREITOS HUMANOS SOBRE TERRAS INDÍGENAS E A ADOÇÃO DA TEORIA DO INDIGENATO. 648

Eduardo Augusto Salomão Cambi, Elisângela Padilha e Pedro Gustavo Mantoan Rorato

7. Grupos VULNERÁVEIS E TRANSFORMAÇão

Ius Constitucionale Commune na América Latina: a Corte Interamericana de Direitos Humanos COMO INSTRUMENTO DE FIXAÇÃo DE STANDARDS PROTETIVOS AOS DiREITOS

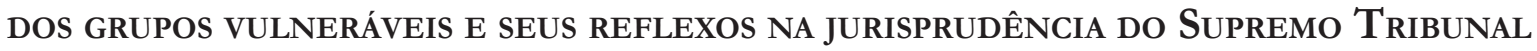
FEDERAL .666 Mônia Clarissa Hennig Leal e Eliziane Fardin de Vargas 
A eficácia da norma que ousou falar seu nome: os Princípios de Yogyakarta como potênCia densificadora do Ius Constitutionale Commune na América Latina .........687

Tiago Benício Trentini e Luiz Magno Bastos Jr

A Corte Interamericana de direitos humanos e a proteção dos direitos LGBTI: construindo um Ius Constitutionale Commune baseado na diversidade

João Pedro Rodrigues Nascimento, Tiago Fuchs Marino e Luciani Coimbra de Carvalho

LA VIOLENCIA INTRAFAMILIAR EN CONTEXTOS DE COVID-19: REALIDADES DEL AMPARO INSTITUCIONAL A SUJETOS DE ESPECIAL PROTECCIÓN EN ESCENARIOS DE EMERGÊNCIA .737 Víctor Julián Moreno Mosquera, John Fernando Restrepo Tamayo e Olga Cecilia Restrepo-Yepes

O caso Vélez loor vs. Panamá da Corte Interamericana de Direitos Humanos como PARADIGMA PARA A CONSTRUÇÃO DE PARÂMETROS MIGRATÓRIOS LATINO-AMERICANOS .757 Tatiana de A. F. R. Cardoso Squeff e Bianca Guimarães Silva

Direitos HUMANOS E ESTADO DE COISAS INCONSTITUCIONAL: O TRANSCONSTITUCIONALISMO LATINO-AMERICANO NA ADPF No 347 .783

Maiquel Ângelo Dezordi Wermuth e André Giovane de Castro

Trabalho escravo contemporâneo: as contribuições do diálogo ENTRE o Sistema InTERAMERICANo de Direitos Humanos E O Brasil PARA O FORTALECIMENTo dA Dignidade DO TRABALHADOR

Emerson Victor Hugo Costa de Sá, Sílvia Maria da Silveira Loureiro e Jamilly Izabela de Brito Silva

8. Direitos humanos, EMPRESAS e transformaÇão

DiÁlOgos MULTIATOR PARA IMPLEMENTAÇÃO DOS STANDARDS INTERAMERICANOS SOBRE Pandemia e Direitos Humanos

Ana Carolina Lopes Olsen e Anna Luisa Walter Santana

O ENVOLVIMENTO DE EMPRESAS EM VIOLAÇÕES DE DIREITOS HUMANOS E OS IMPACTOS DAS DECISÕES DA CORTE INTERAMERICANA

Patricia Almeida de Moraes e Marcella Oldenburg Almeida Britto

III. OUTRAS PERSPECTIVAS SOBRE TRANSFORMAÇÃO

Pluralismo jurídico e democracia comunitária: Discussões teóricas Sobre DESCOLONIZAÇÃo CONSTITUCIONAL NA BOLÍVIA

Débora Ferrazzo e Antonio Carlos Wolkmer

INTERCULTURALIDADE, PLURINACIONALIDADE E PLURALISMO NAS CONSTITUIÇÕES DO EQUADOR E DA BOLÍVIA: EXPOENTES PRINCIPIOLÓGICOS DO ESTADO PLURINACIONAL .897 Denise Tatiane Girardon dos Santos 
IUS COMMUNE: ENTRE O PLURALISMO JURISDICIONAL DIALÓGICO E A ADOÇÃO DE NORMAS ALTERATIVAS .

Ana Maria D'Ávila Lopes 


\title{
Interculturalidade, plurinacionalidade e pluralismo nas constituições do Equador e da Bolívia: expoentes principiológicos do estado plurinacional*
}

\author{
Interculturality, plurinationality and \\ pluralism in the constitutions of Ecuador \\ and Bolivia: principiological exponents of the \\ plurinational state
}

Denise Tatiane Girardon dos Santos**

\section{Resumo}

As experiências políticas descoloniais de países latino-americanos, como o Equador e a Bolívia, trouxeram inovações ao pensamento político moderno, com expoentes no constitucionalismo latino-americano e no Estado Plurinacional. Nesse sentido, o objetivo deste Artigo é identificar princípios do Estado Plurinacional, insculpidos nas Constituições Equatoriana e Boliviana, alicerçados nas cosmovisões do Sumak Kawsay (Equador) e Suma Qamaña (Bolívia), e enquanto elementos inéditos no campo da Teoria do Estado. A pergunta que se pretende responder é: a interculturalidade, a pluralidade e o pluralismo se apresentam como fundamentos principiológicos do Estado Plurinacional, e avançam na evolução constitucional desde a América Latina? Como hipótese, as experiências políticas latino-americanas descoloniais conduziram à refundação do Estado, ressignificado pela perspectiva plurinacional, em que inéditas visões, lexos e, por decorrência, princípios, lastreiam seu Documento fundante, que é a Constituição. Teoricamente, as Constituições dos Estados Plurinacionais asseveram o enfrentamento das características estatais, até então, modernas, eurocêntricas e uniformes. As inovações principiológicas, que caracterizam a Teoria do Estado Plurinacional, refletem o repensar do Estado desde o Sul e, a partir de formas de vida e organizações próprias, que permeiam, transversalmente, as Constituições. A estratégia da pesquisa é explicativa e propositiva; a natureza da abordagem é qualitativa, e o método utilizado foi o dedutivo.

* Recebido em 31/05/2021

Aprovado em 07/10/2021

** Doutora em Direito pela Universidade do Rio dos Sinos - UNISINOS. Professora Permanente do Programa de Pós-Graduação Stricto Sensu em Práticas Socioculturais e Desenvolvimento Social (PPGPSDS) e do Curso de Direito da Universidade de Cruz Alta -UNICRUZ. Pesquisadora FAPERGS. Pesquisadora do Laboratório de Pesquisas Avançadas em Direito Internacional e Ambiental - LEPADIA/UFRJ. E-mail: dtgsino@hotmail.com.
Palavras-chave: Sumak Kawsay e Suma Qamaña; Interculturalidade; Plurinacionalidade; Pluralismo; Estado Plurinacional; Constitucionalismo Latino-americano.

\section{Abstract}

The political experiences of some Latin American countries, such as Equator and Bolivia, have brought innovations to modern political thought, with exponents in Latin American constitutionalism and the Plurinational State. 
In this sense, the objective of this Article is to identify principles of the Plurinational State, inscribed in the Ecuadorian and Bolivian Constitutions, based on the worldviews of Sumak Kawsay (Ecuador) and Suma Qamaña (Bolivia), and as unpublished elements for the State Theory. The question to be answered is: do interculturality, plurality and pluralism are principles foundations of the Plurinational State, and do they advance in constitutional evolution since Latin America? As a hypothesis, the decolonial Latin American political experiences led to the refoundation of the State, resignified by the plurinational perspective, in which unprecedented visions, lexus and, as a result, principles, that support the founding Document: the Constitution. Theoretically, the Constitutions of Plurinational States assert the confrontation of state characteristics, until then, modern, eurocentric and uniform. The principiological innovations, which characterize the Plurinational State theory, reflect the rethinking of the State from the South and from its own forms of life and organizations, which permeate, transversely, the Constitutions. The research strategy is explanatory and propositional; the nature of the approach is qualitative and the method used was deductive.

Keywords: Sumak Kawsay and Suma Qamaña; Interculturality; Plurinationality; Pluralism; Plurinational State; Latin-American Constitutionalism.

\section{Introdução}

A primeira década do século XXI foi marcada pela promulgação de duas Constituições, com inovações basilares, inclusive, na Teoria do Estado, quais sejam, a Constitución de la República del Ecuador, de 2008, e na Constitución Politica del Estado Boliviana, de 2009. Dentre os expoentes do constitucionalismo latino-americano, ambas serão consideradas nesta pesquisa considerando-se o percurso histórico dos movimentos descoloniais, agentes do giro descolonial, do qual decorreu a alteração fundante dos Estados, por intermédio da Constituição Plurinacional.

O objetivo da pesquisa, é, pelo estudo dos Textos constitucionais Equatoriano e Boliviano, identificar princípios do Estado Plurinacional, considerando-se inserções como as cosmovisões do Sumak Kawsay (Equador) e Suma Qamaña (Bolívia), a transversalidade e o ineditismo na Teoria Constitucional, e em que medida o constitucionalismo latino-americano está consolidado nesses fundamentos principiológicos. Dessa forma, o problema de pesquisa é apontar se a interculturalidade, a pluralidade e o pluralismo configuram-se como fundamentos principiológicos do Estado Plurinacional, e avançam na evolução constitucional desde a América Latina, sob o prisma do movimento de ruptura com as características coloniais.

A análise será de cunho teórico, e se voltará para a interculturalidade, a pluralidade e o pluralismo como potenciais princípios do Estado Plurinacional, enquanto rol exemplificativo. Não há pretensão de exaurir a carga principiológica constitucional plurinacional ou apontar o seu grau de efetividade material. Esta pesquisa considera, como hipótese, que a atuação dos movimentos sociais descoloniais foram intensos ao ponto de produzirem alterações significativas na Constituição dos Estados, inserindo suas pautas na agenda estatal, antes, monista, uniforme e de desenhos eurocêntricos, e que, agora, alicerça, legitimamente, o prosseguimento das reivindicações descoloniais. Identificar princípios plurinacionais nas Constituições pode contribuir para o fortalecimento das perspectivas sociais plurais desde a América Latina, dos povos e grupos enquanto sujeitos constituídos e constituintes, e com o enfrentamento das características estatais colonialistas.

As estratégias da pesquisa serão, na primeira Seção, a explicativa, com fins de contextualizar as experiências dos movimentos que avançaram para as alterações constitucionais; a descritiva, na segunda Seção, visando a apontar, nas Constituições, a interculturalidade, a plurinacionalidade e o pluralismo como supedâneos para a estruturação do Estado e, por fim, na terceira Seção, a propositiva, ao se argumentar que tais elementos podem se constituir em princípios dos Estados plurinacionais, oriundos de modos próprios de vida, cosmovisões e organização, até então, suprimidos pela imposição de teorias ocidentais importadas. 
Os dados são os relacionados aos temas investigados e às proposições da pesquisa, com a finalidade de obtenção de elementos capazes de provar a hipótese levantada. A natureza da abordagem é qualitativa, com pesquisas documental e bibliográfica. Os subsídios teóricos-metodológicos acompanharam o método dedutivo.

\section{Considerações sobre os movimentos descoloniais e o Estado Plurinacional no Equador e na Bolívia}

A América Latina foi marcada por movimentos de resistência ao colonialismo e, posteriormente, à colonialidade, esta que se manteve após as independências. Os movimentos sociais protagonizaram grandes alterações nos arranjos dos Estados, culminando, alguns, na implementação de Estados Plurinacionais, a exemplo do Equador e da Bolívia ${ }^{1}$.

A colonialidade permaneceu insculpida nas bases oligárquicas colonialistas, que, frente à negativa das metrópoles em conceder-lhes espaço nas decisões político-administrativas, se articularam para a promoverem as independências nacionais. Esses grupos mantiveram, nos novos Estados, política e juridicamente, a estrutura social e econômica desigual, com défice democrático, em que o povo, para Comparato, era "[...]

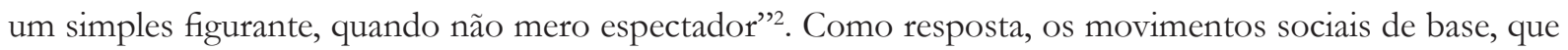
conduziriam às alterações constitucionais do início do século XXI, passaram a ter maior articulação a partir de 1970, e, desses sujeitos oprimidos latino-americanos, para Souza, “[...] nasceu um conjunto de teorias próprias do subcontinente que mira nele suas questões existenciais”’ , como as Constituições dos Estados Plurinacionais.

No Equador, as proporções nacionais de resistência foram possíveis com a organização da Confederación de Nacionalidades Indígenas del Ecuador (CONAIE), a partir 1980, expoente de uma onda social, caracterizada por "[...] una intelectualidad indígena y una dirigencia autónoma formada en la lucha por la tierra y por el reconocimiento", de acordo com Maldonado. A busca pelo mandato ancestral, pautado nas premissas de abi tenemos el ama shwa, ama llulla, ama killa - no robar, no mentir, no ser ocioso, perfilhou o consenso comunal que visava a decisões e resoluções de conflitos democráticas.

Na década seguinte, o Movimento de Unidade Plurinacional de Pachakutik liderou exigências por demandas dos campesinos, sem desconsiderar as de outros grupos minoritários, inclusive, na reivindicação de uma Constituinte que comportasse pautas "[...] no solamente de los pueblos indígenas sino del conjunto de grupos sociales excluidos del que hacer democrático", segundo Maldonado. A Constituição de 1998 foi um marco importante, porque reconheceu o Estado pluricultural e multiétnico e os Derechos colectivos de los pueblos indígenas y negros o afroecuatorianos, grupos que prosseguiram com as reivindicações. Nos anos 2000, os movimentos indígenas protagonizaram o espaço político e, em 15 de janeiro de 2007, o representante indígena Rafael Correa foi eleito presidente. Correa convocou uma Assembleia Constituinte, da qual resultou a Constitución de la República del Ecuador, promulgada em 28 de setembro de 2008. ${ }^{\circ} \mathrm{Na}$ Bolívia, foram mantidas as estruturas sociais colonialistas classificatórias, pautadas na cor da pele, na propriedade, no idioma, dentre

\footnotetext{
1 ALBÓ, Xavier. Movimientos y poder indígena en Bolivia, Ecuador y Perú. La Paz: Cipca, 2008.

2 COMPARATO, Fábio Konder. Prefácio. In: FAORO, Raymundo. A República inacabada. São Paulo: Globo, 2007. p. 17.

3 SOUSA, Adriano Corrêa de. A emancipação como objetivo central do novo constitucionalismo latinoamericano: os caminhos para um constitucionalismo da libertação. In: VAL, Eduardo Manuel; BELLO, Enzo. O pensamento pós e descolonial no novo constitucionalismo latino-americano. Caxias do Sul: Educs, 2014. p. 66.

4 MALDONADO, Ana María Larrea. El movimiento indígena ecuatoriano: participación y resistencia. Observatorio Social de América Latina, v. 5, n. 13, p. 67-76, 2004, p. 68.

5 MALDONADO, Ana María Larrea. El movimiento indígena ecuatoriano: participación y resistencia. Observatorio Social de América Latina, v. 5, n. 13 , p. 67-76, 2004, p. 69.

6 CORREA, Rafael. Equador: da noite neoliberal à revolução cidadã. São Paulo: Boitempo, 2015. p. 53.
} 
outros. Os bolivianos (a grande maioria, formada por indígenas, negros e/ou não falantes da língua espanhola) e ciudadanos (a pequena minoria, representada na oligarquia criolla, branca e com domínio do Castelhano) restringia aqueles do exercício da cidadania, pois, somente a estes era permitido o voto e a assunção em cargos públicos. O voto universal foi instituído com a Constituição de 1947, mas ser nacional e ser cidadão dependia do domínio da Língua Castellana, de modo que, para Alvar, “[...] para ser cuidadano es necesario 'saber ler y escribir"'?

A partir de 1970, representantes dos povos indígenas, sobretudo, quíchuas e aymaras, se inseriram nas disputas eleitorais, contribuindo para a abertura democrática do país. Nos anos 1990, as resistências aos reflexos da crise neoliberal criaram, nas palavras de Valença, “[...] um cenário de rearranjos político-institucionais que colocam em xeque os aspectos da teoria democrática consolidados no século XX" . Os anos 2000 iniciaram com confrontos, principalmente, em defesa dos recursos naturais, como água e gás, e, da ebulição social, nas eleições de 18 de dezembro de 2005, Juan Evo Morales Aima foi eleito presidente. ${ }^{9}$ Em 2007, Morales realizou um Asamblea Constituyente e promulgou a Constitución Politica del Estado em 07 de fevereiro de 2009.

O período de 1990 até as Constituintes Plurinacionais do Equador e da Bolívia foi marcado pela interculturalidade, supedâneo de demandas, propostas e ações que, segundo Mignolo e Walsh, "[...] estabeleceram o significado sociopolítico e a fundação da interculturalidade no Equador e na região andina". ${ }^{10}$ Os projetos sociais refletiram em transformações de impactos estruturais, de ordem "[...] econômica, social, judicial e política, e visavam à construção de uma sociedade plurinacional e intercultural em culturas indígenas e outras culturas, povos e conhecimentos excluídos historicamente, e conhecimentos considerados constitutivos"11.

Esse cenário repercute as experiências políticas, culturais, econômicas, de conhecimento, ocultadas pelo eurocentrismo, enquanto “[...] o movimento de resistência teórico e prático, político e epistemológico, à lógica da modernidade/colonialidade" ${ }^{12}$, segundo Ballestrin. A filosofia dialógica entre a teoria e a prática dos movimentos representam, pois, o giro descolonial ${ }^{13}$, a não indiferença ante o Outro.

A combinação de formas de resistência originárias, a multiplicidade de comunicações e articulações entre povos indígenas, afroequatorianos/afrobolivianos, as comunidades e grupos marginalizados de trabalhadores, estudantes, além dos “[...] llamados nuevos movimientos como los de género, los ecologistas, los de deudores y jubilados, y en general los de los empobrecidos, marginados, excluidos, desempleados, desplazados, y amenazados de extinción" ${ }^{14}$, como enumera Casanova, viabilizaram discutir a própria noção de Estado. ${ }^{15}$

\footnotetext{
7 ALVAR, Manuel. Lengua nacional y sociolinguística: las constituciones de América. Bulletin hispanique, v. 84, n. 3, p. 347-414, 1982. p. 355-356.

8 VALENÇA, Daniel Araújo. Bolívia: crise de Estado, disputa hegemônica e ressignificação democrática. In: VAL, Eduardo Manuel; BELLO, Enzo. O pensamento pós e descolonial no novo constitucionalismo latino-americano. Caxias do Sul: Educs, 2014. p. 92.

9 LINERA, Álvaro García. A potência plebeia. São Paulo: Boitempo, 2010.

10 Texto original: "[...] established the sociopolitical significance and foundation of interculturality in Ecuador and the Andean region”. MIGNOLO, Walter; WALSH, Catherine. On decoloniality: concepts, analytics, práxis. Durham: Duke University Press, 2018. p. 60 .

11 Texto original: "[...] economic, social, judicial, and political spheres and were aimed toward the construction of a plurinational and intercultural society in witch Indigenous and other historically excluded cultures, peoples, and knowledges would be considered constitutive". MIGNOLO, Walter; WALSH, Catherine. On decoloniality: concepts, analytics, práxis. Durham: Duke University Press, 2018. p. 61.

12 BALLESTRIN, Luciana. América Latina e o giro decolonial. Revista brasileira de ciência política, n. 11, p. 89-117, 2013. p. 105.

13 Termo cunhado por Nelson Maldonado-Torres. A expressão giro está atrelada ao campo epistemológico e indica o redirecionamento de um assentamento epistêmico, um universo de sentido. Os giros “[...] plantean que ya sea el universo del sentido en general o el de los actos de habla proveen las claves fundamentales para entender las formas en que nuestro mundo, es decir el mundo humano preñado de significado, opera". MALDONADO-TORRES, Nelson. La descolonización y el giro des-colonial. Tabula rasa, n. 9, 2008. p. 66.

14 CASANOVA, Pablo González. Colonialismo interno (una redefinición). Colonialismo interno (una redefinición). In: BORON, Atilio A.; AMADEO, Javier; GONZÁLEZ, Sabrina (Comp.). La teoría marxista hoy. Problemas y perspectivas. Buenos Aires, CLACSO, 2006. p. 419.

15 VALENÇA, Daniel Araújo. Bolívia: crise de Estado, disputa hegemônica e ressignificação democrática. In: VAL, Eduardo Manuel; BELLO, Enzo. O pensamento pós e descolonial no novo constitucionalismo latino-americano. Caxias do Sul: Educs, 2014 , p. 99.
} 
O modelo estatal europeu, moderno, monista e excludente foi redefinido pelo paradigma da plurinacionalidade, avocada na Constitución de la República del Ecuador e na Constitución Politica del Estado da Bolívia, expoentes do chamado constitucionalismo latino-americano.

A Constituição Equatoriana enaltece, preambularmente, “[...] nuestras raíces milenarias, forjadas por mujeres y hombres de distintos pueblos", que embazaram "una nueva forma de convivencia ciudadana, en diversidad y armonía com la naturaleza, para alcanzar el buen vivir, el sumak kawsay", em que o buen vivir, nas palavras de Mignolo e Walsh, “[...] é entendido como a interrelação ou correlação harmoniosa de e entre todos os seres (humanos e outros) e com o seu entorno"16, e "[...] una sociedad que respeta, en todas sus dimensiones, la dignidad de las personas y las colectividades" ${ }^{17}$. No artigo primeiro, a Constituição declara que:

Art. 1. El Ecuador es un Estado constitucional de derechos y justicia social, democrático, soberano, independiente, unitario, intercultural, plurinacional y laico. Se organiza en forma de república y se gobierna de manera descentralizada.

Por sua vez, a Constituição Boliviana, preambularmente, alude à antropológica formação plural dos povos e culturas, e declara o nuevo Estado pelo poder originário do povo. Afastou a nacionalidade monista e acolheu as nacionalidades coexistentes ${ }^{18}$ e todas as formas de organização social enquanto expressões de soberania popular. Em seu artigo primeiro, a Constituição assevera:

Artículo 1. Bolivia se constituye en un Estado Unitario Social de Derecho Plurinacional Comunitario, libre, independiente, soberano, democrático, intercultural, descentralizado y con autonomías. Bolivia se funda en la pluralidad y el pluralismo político, económico, jurídico, cultural y lingüístico, dentro del proceso integrador del país.

Casanova explica que os processos, dos quais decorreram as Constituições mencionadas, resultaram em um Estado multiétnico, vinculado “[...] a la construcción de 'un mundo hecho de muchos mundos' que tendría como protagonistas a los pueblos, los trabajadores y los ciudadanos" ${ }^{\prime 1}$. As lutas políticas, as experiências institucionais e os movimentos teóricos convergentes conduziram, para Leonel Júnior, "[...] a descrição de inovações políticas e jurídicas introduzidas nesses contextos”20.

As Constituições do Equador e da Bolívia, Documentos fundantes do Estado, declararam a emergência de um paradigma sociopolítico epistemológico, que, segundo Fajardo, “[...] impactaram sobre la configuración del Estado propiamente dicho, permitiendo vislumbrar el horižonte del constitucionalismo pluralista" 21 . As Constituições dos Estados Plurinacionais são genuínas expressões político-jurídicas descoloniais, porque foram orientadas na interculturalidade, pautadas na plurinacionalidade e estabelecidas em convergência ao pluralismo, elementos que são considerados, neste Artigo, como princípios do Estado Plurinacional.

\footnotetext{
16 Texto original: "[...] is understood as the harmonious interrrelation or correlation of and among all beings (human and otherwise) and whith their surroundings". MIGNOLO, Walter; WALSH, Catherine. On decoloniality: concepts, analytics, práxis. Durham: Duke University Press, 2018. p. 64.

17 Preâmbulo. Constituição do Equador.

18 Artigo 6.

19 CASANOVA, Pablo González. Colonialismo interno (una redefinición). In: BORON, Atilio A.; AMADEO, Javier; GONZÁLEZ, Sabrina (Comp.). La teoría marxista hoy. Problemas y perspectivas. Buenos Aires, CLACSO, p. 409-434, 2006. p. 413.

20 LEONEL JÚNIOR, Gladstone. O novo constitucionalismo latino-americano: um estudo sobre a Bolívia. $2^{\mathrm{a}}$ ed. Rio de Janeiro: Lumen Juris, 2018. p. 55.

21 FAJARDO, Raquel Z. Yrigoyen. El horizonte del constitucionalismo pluralista: del multiculturalismo a la descolonización. In: GARAVITO, César Rodríguez (Coord.). El derecho en América Latina: um mapa para el pensamento jurídico del siglo XXI. Buenos Aires: Siglo Veinteuno, 2011. p. 139.
} 


\section{Interculturalidade, plurinacionalidade e pluralismo nas Constituições Plurinacionais}

Nas Constituições do Equador e da Bolívia, expoentes do constitucionalismo plurinacional podem ser identificados e princípios do Estado Plurinacional, quais sejam, a interculturalidade, a plurinacionalidade e o pluralismo, este, nas perspectivas política, jurídica, econômica, cultural, linguística, educacional e de sujeitos, como a Natureza. As cosmovisões Sumak Kawsay e Suma Qamaña são, ao mesmo tempo, meio e fim desses princípios, porque, insertas nas Constituições, asseguram elementos de coexistência, solidariedade e alteridade, inéditos no constitucionalismo.

Os Preâmbulos dos Textos constitucionais, como mencionado, expressam as pretensões de "una nueva forma de convivencia ciudadana, en diversidad y armonía con la naturaleza, para alcanzar el buen vivir, el sumak Kawsay"22, do Equador, e "un Estado basado en el respeto e igualdad entre todos, con principios de soberanía, dignidad, complementariedad, solidaridad, armonía y equidad en la distribución y redistribución del producto social, donde predomine la búsqueda del vivir bien”23 da Bolívia.

A interculturalidade, que pautou os movimentos descolonizantes, agentes da consolidação teórica do Estado Plurinacional, na expressão constitucional, circundou a pauta da refundação do espaço político ${ }^{24}$. Mignolo e Walsh apontam o respeito à diversidade de nações, povos e setores sociais e a exigência de sua unidade "[...] nos campos econômico, social, cultural e político, com vistas a transformar as estruturas atuais e a construir um novo estado plurinacional, no quadro da igualdade de direitos, respeito mútuo, paz, e harmonia entre nacionalidades e povos" ${ }^{25}$.

A interculturalidade contrapõe e desestabiliza o poder dominante, calcado na economia capitalista, ao preconizar a complementaridade e a relacionalidade constitutiva das cosmovisões nos espaços socioeconômicos. Trata-se de um projeto político, epistêmico, existencial e, por decorrência, descolonial, de diálogo e/ ou interrelação entre culturas para a “[...] construção de sociedades radicalmente diferentes, de uma 'outra' ordem social e de transformações estruturais econômicas, sociais, políticas e culturais" ’26, como explicam Mignolo e Walsh.

Mignolo e Walsh também destacam o processo permanente e ativo de negociação e interrelação entre compreensões, coexistências, solidariedades e colaborações. A interculturalidade figura como âncora de proposta, processo e projeto de "[...] transformar, reconceituar e refazer estruturas e instituições de maneira que coloquem em relações equitativas (mas ainda conflitivas) diversas lógicas, práticas e maneiras de conhecer, pensar, agir, ser e viver" ${ }^{\prime 2}$, motivos pelos quais se apresenta como um princípio do Estado Plurinacional.

A plurinacionalidade reflete-se na rejeição à ideia de nação monista, restrita em um território, delimitado, geopoliticamente, pelos colonizadores, em desconsideração às formações sociais anteriores/diferentes, e com um único povo e forma de vida, concepção, até então, refletida nas Constituições anteriores. Trata-se de "[...] concepto de nación conlleva un concepto de autodeterminación pero no de independencia" 28 , como

\footnotetext{
22 ASAMBLEA CONSTITUYENTE DE ECUADOR. Constitución de la República del Ecuador. Quito: Registro Oficial, 2008.

23 ESTADO PLURINACIONAL DE BOLIVIA. Constitución politica del Estado. La Paz: Gaceta Oficial del Estado Plurinacional de Bolivia, 2009.

24 WOLKMER, Antonio Carlos; FAGUNDES, Lucas Machado. Para um novo paradigma de estado plurinacional na América Latina. Novos Estudos Jurídicos, v. 18, n. 2, p. 329-342, 2013, p. 340.

25 MIGNOLO, Walter E.; WALSH, Catherine E. On decoloniality: concepts, analytics, práxis. Durham: Duke University Press, 2018.

26 Texto original: "[...] it points toward the building of radically diferent societies, of na 'other' social ordering, and of structural economic, social, political, and cultural transformations". MIGNOLO, Walter; WALSH, Catherine. On decoloniality: concepts, analytics, práxis. Durham: Duke University Press, 2018. p. 57.

${ }_{27}$ Texto original: "[...] transform, reconceptualize, and refound structures and institutions in ways that put in equitable (but still conflitive) relation diverse cultural logics, practices, and ways of knowing, thinking, acting, being, and living". MIGNOLO, Walter; WALSH, Catherine. On decoloniality: concepts, analytics, práxis. Durham: Duke University Press, 2018. p. 59.

28 SANTOS, Boaventura de Sousa. Pensar el Estado y la sociedad: desafíos actuales. Buenos Aires: Waldhuter Editores, 2009. p. 203.
} 
explica Santos, e se expressa na organização e convivência intercultural de formas sociais autênticas.

A Constituição do Estado Plurinacional rompe com a epistemologia da uniformidade e da unificação, ao possibilitar, de acordo com Santos, “[...] otro concepto de nación, concebida como pertenencia común a una etnia, cultura o religión” 29 , e comportar a concepção dos novos sujeitos coletivos, com espaços e categorias adequadas às suas inteligibilidades. Em substituição ao reconhecimento passivo da diferença, o Estado Plurinacional é, em si, constituído nos povos formadores, soberanos, dotados de autodeterminação, de autonomia e de autogoverno, exercidos pelas instituições e entidades territoriais, e se constituem, para Schavelzon, como "[...] um marco para o desenvolvimento de futuras disputas que aflorarão na elaboração de suas normas e em sua implementação" 30 .

A Constituição do Equador prevê, no artigo $6^{\circ}$, a nacionalidade como vínculo da pessoa com o Estado e com as nacionalidades indígenas, já que o Estado, único e indivisível, é formado por "las comunidades, pueblos, y nacionalidades indígenas, el pueblo afroecuatoriano, el pueblo montubio y las comunas [...]" (artigo 56). A Bolívia declarou a unidade do Estado sob o marco pré-colonial das nações e povos indígenas originários campesinos, assim como dos afrobolivianos, que detêm livre determinação, "[...] autonomía, al autogobierno, a su cultura, al reconocimiento de sus instituciones y a la consolidación de sus entidades territoriales" (artigo $2^{\circ}$ ). Pessoas, nações e povos indígenas, comunidades interculturais e afrobolivianas compõem o Estado, e as nacionalidades podem ser adquiridas por nascimento ou naturalização, nos trinta e seis grupos étnicos ${ }^{31}$.

As Constituições do Equador e da Bolívia preveem que o controle e a gestão são populares, a exemplo da Función de Transparencia y Control Social e da Participación y Control Social respectivamente, e designam ao Estado a responsabilidade de assegurar as condições para preservação e desenvolvimento pelo horizonte plurinacional. ${ }^{32}$ A plurinacionalidade alicerça sociedades multiculturais e propõe a reformulação hermenêutica e legal das instituições, pois, consoante Grijalva, viabiliza [...] um tipo de constitucionalismo novo, baseado em relações interculturais igualitárias que redefinam e reinterpretem os direitos constitucionais, reestruturando a institucionalidade advinda do Estado nacional" "33, com condições de espaços de deliberação intercultural democrática.

Declarar-se plurinacional é registrar e aproximar no/do Documento político a formação plúrima e equivalente, pois, de acordo com Santos, "el constitucionalismo intercultural y plurinacional está haciendo, de diferentes maneras, una equivalencia entre lo que es simultáneo y lo que es contemporáneo"34. A plurinacionalidade é um princípio do Estado Plurinacional por negar as estruturas coloniais de poder e alçar os sujeitos políticos a sujeitos constituintes ${ }^{35}$, e "[...] voltar a atenção ao oprimido e devolver para ele sua dignidade"36, conforme Sousa. Destacam-se, como meios, os mecanismos de democracia ampliada, como são os plebiscitos, e o pluralismo, este, que, para Sousa, “[...] que não se limita ao aspecto político, promovendo a

29 SANTOS, Boaventura. Refundación del Estado en América Latina: perspectivas desde una epistemología del Sur. La Paz: Plural, 2010. p. 287.

30 SCHAVELZON, Salvador Andrés. As Categorias Abertas da Nova Constituição Boliviana. Formação do Estado Plurinacional: Alguns Percursos Intelectuais. Revista Lugar Comum, n. 27, p. 35 - 60, 2009. p. 38.

31 Vide artigos: $1^{\circ}$, 30.I, 32, 141. Os grupos étnicos são: Quechua, Aymara, Chiquitano, Guaraní, Mojeño, Afroboliviano, Guarayo, Movima, Tacama, Itonama, Leco, Kallawaya, T’simane, Yuracaré, Weenhayek, Maropa, Joaquiniano, Baure, Cavineño, Mosetén, Ayoreo, Cayubaba, Araona, Chácobo, Chipaya, Esse Ejja, Canichana, Sirionó, Yucararé-Mojeño, Yuki, Pacahuara, Moré, Murato, Yaminahua, Tapiete, Guarasugwé e Machinerí.

32 Vide artigos: 204 e 380.1 (Equador) e 9 e 241.I (Bolívia).

33 GRIJALVA, Agustín. O Estado Plurinacional e Intercultural na Constituição Equatoriana de 2008. In: VERDUM, Ricardo. Povos indígenas: Constituições e reformas políticas na América Latina. Brasília: Instituto de Estudos Socioeconômicos, 2009. p. 115.

34 SANTOS, Boaventura de Sousa. Pensar el Estado e la sociedad: desafios actuales. Buenos Aires: Waldhuter, 200., p. 207.

35 FAJARDO, Raquel Z. Yrigoyen. El horizonte del constitucionalismo pluralista: del multiculturalismo a la descolonización. In: GARAVITO, César Rodríguez (Coord.). El derecho en América Latina: um mapa para el pensamento jurídico del siglo XXI. Buenos Aires: Siglo Veinteuno, p. 139-160, 2011.

36 SOUSA, Adriano Corrêa de. A emancipação como objetivo central do novo constitucionalismo latinoamericano: os caminhos para um constitucionalismo da libertação. In: VAL, Eduardo Manuel; BELLO, Enzo. O pensamento pós e descolonial no novo constitucionalismo latino-americano. Caxias do Sul: Educs, 2014. p. 66. 
refundação do Estado com base em premissas diferentes daquelas que caracterizaram durante muito tempo o Estado moderno de tipo europeu" 37 .

Por fim, o pluralismo, diante da insuficiência do modelo clássico ocidental, aponta para um novo paradigma de legalidade, democrático, antidogmático, assentado nas condições históricas e atuais e das práticas sociais reais e insurgentes, ao pressupor a complexidade da "[...] existência de mais de uma realidade, de amplas formas de ação e da diversidade de campos sociais com particularidade própria"38, como aponta Wolkmer. Está refletido nas searas política, jurídica, econômica, cultural, linguística, além do cuidado com a Natureza, alçada como sujeito de direito. ${ }^{39}$ Neste Artigo, para fins de abordagem e exemplificação, serão pontuados, na sequência, os pluralismos político, jurídico, econômico e de sujeitos.

O pluralismo político, para Vargas, “[...] deixa de lado as 'políticas de reconhecimento’ para entrar em cheio no que hoje denominamos na Bolívia e no Equador de políticas de descolonização"40. A Constituição Plurinacional assegura aos povos o protagonismo da condução do Estado, enquanto novos sujeitos sociais de juridicidade $e^{41}$, porque se conjura em “[...] conjunto normativo de densidade democrática e pluralista até então não experimentados no âmbito do constitucionalismo regional [...] transformador da realidade social e originador de uma nova matriz de pensamento"42, como destaca Sousa.

Um dos deveres do Equador ${ }^{43}$ é "fortalecer la unidad nacional en la diversidad" (artigo 3.3), do que decorre, diretamente, os Derechos de las comunidades, pueblos y nacionalidades. Passou de reconhecimento de direitos aos povos para afirmação do Estado a partir dos povos (artigo 56), ou seja, povos como origem (ativos), não como destinatários (passivos). Destaca-se a Participación en democracia, orientada pela "[...] igualdad, autonomía, deliberación pública, respeto a la diferencia, control popular, solidaridad e interculturalidad”, e exercida por "[...] mecanismos de la democracia representativa, directa y comunitária" (artigo 95). Evidenciam-se os gobiernos autónomos descentralizados, que se orientam em princípios gerais, e asseguram o gozo da "[...] autonomía política, administrativa y financiera, y se regirán por los principios de solidaridad, subsidiariedad, equidad interterritorial, integración y participación ciudadana" (artigo 238).

$\mathrm{Na}$ Bolivia ${ }^{44}$, os Derechos de las naciones y pueblos indígena originário campesino referendam o arranjo plurina-

\footnotetext{
37 SOUSA, Adriano Corrêa de. A emancipação como objetivo central do novo constitucionalismo latinoamericano: os caminhos para um constitucionalismo da libertação. In: VAL, Eduardo Manuel; BELLO, Enzo. O pensamento pós e descolonial no novo constitucionalismo latino-americano. Caxias do Sul: Educs, 2014. p. 66.

38 WOLKMER, Antonio Carlos. Pluralismo Jurídico. Fundamentos de uma nova cultura do Direito. 4. ed. São Paulo: Saraiva, 2015. p. 11. Disponível em: https://books.google.com.br/books?isbn=8502228366. Acesso em: 10 Abr. 2021.

39 SANTOS, Denise Tatiane Girardon dos. Estados Plurinacionais na América Latina: cenários para o republicanismo na contemporaneidade. Curitiba: CRV, 2020.

40 VARGAS, Idón Moisés Chivi. Os caminhos da descolonização na América Latina: os Povos Indígenas e o igualitarismo jurisdicional na Bolívia In: VERDUM, Ricardo. Povos indígenas: Constituições e reformas políticas na América Latina. Brasília: Instituto de Estudos Socioeconômicos, p. 151-166, 2009, p. 164.

41 WOLKMER, Antonio Carlos. Pluralismo Jurídico. Fundamentos de uma nova cultura do Direito. 4. ed. São Paulo: Saraiva, 2015, p. 11. Disponível em: https://books.google.com.br/books?isbn=8502228366. Acesso em: 10 Abr. 2021.

42 SOUSA, Adriano Corrêa de. A emancipação como objetivo central do novo constitucionalismo latinoamericano: os caminhos para um constitucionalismo da libertação. In: VAL, Eduardo Manuel; BELLO, Enzo. O pensamento pós e descolonial no novo constitucionalismo latino-americano. Caxias do Sul: Educs, 2014. p. 65.

43 São expoentes do pluralismo político na Constituição Equatoriana, inseridos no Título I, Elementos Constitutivos del Estado, os Princípios fundamentales (artigos $1^{\circ}$ a $4^{\circ}$ ); Título II, Derechos, os Principios de aplicación de los derechos (artigos 10 e 11) e os Derechos de las comunidades, pueblos y nacionalidades (artigos 56 a 60); Título III, Garantías Constitucionales, as Garantías normativas (artigo 84) e Garantías Jurisdicionales (artigos 86 ao 94); Título IV, Participación y Organización del Poder, a Función Judicial y justicia indígena (artigos 167 a 203 ).

44 São expoentes do pluralismo político na Constituição Boliviana, inseridos na Primera Parte: Bases Fundamentales del Estado, Derechos, Deberes y Garantías, o Título II, Derechos Fundamentales y Garantías, os Derechos políticos (artigos 26 a 29) e, os Derechos de las naciones y pueblos indígena originário campesino (artigos 30 a 32); Na Segunda Parte: Estructura y Organización Funcional del Estado, o Título I, Órgano Legislativo, com destaque para a Composición y atribuiciones de la Asamblea Legislativa Plurinacional (artigos 145 a 161), o Título II, Órgano Ejecutivo (artigos 165 a 177), o Título IV, Órgano Electoral (artigos 205 a 212) e Representación Política (artigos 209 a 212) e o Título VI, Participación y Control Social (artigos 241 a 242). Na Tercera Parte: Estructura y Organización Territorial del Estado, no Titulo I, Organización territorial del Estado, os capítulos que tratam sobre os Disposiciones generales (artigos 269 a 276), Autonomia departamental (artigos 277 a 279), Autonomia regional (artigos 280 a 282 ),
} 
cional, por declararem a ancestralidade das coletividades e seus direitos no marco da unidade do Estado. A Bolívia “[...] adopta para su gobierno la forma democrática participativa, representativa y comunitaria, con equivalencia de condiciones entre hombres y mujeres" (artigo 11.). A democracia comunitária é exercida “[...] por medio de la elección, designación o nominación de autoridades y representantes por normas y procedimientos próprios" (artigo 11.2), e, nesse sentido, Valença aponta que a recuperação dos “[...] mecanismos democráticos da forma multidão e supera os limites da democracia representativa, para aumentar a soberania popular e o controle social sobre os órgãos do Estado"45. A organização territorial-administrativa comporta os territorios indígena originario campesinos ${ }^{46}$, em que os povos e comunidades indígenas gerem o funciomanento de seus territórios.

As previsões da Constituição Boliviana refletem o pluralismo político e impactam a condução do Estado. Assim como o Equador, preocupou-se com a “[...] regulamentação de um amplo leque de direitos, além de ser muito minuciosa e inclusiva ao selecionar os direitos que devem tornar-se constitucionais" ${ }^{47}$, segundo Ramírez. Leonel Júnior aponta que a diversidade democrática “[...] alimenta o caráter de soberania popular latente e a intervenção concreta dos povos na realidade e cotidiano da sociedade" ${ }^{48}$.

O pluralismo jurídico pode ser verificado na estrutura político-administrativa dos Estados Plurinacionais, dada, conforme Santos, à coexistência de várias ordens jurídicas no espaço geopolítico, "[...] sendo as regras, regulamentos e prescrições produzidas a partir de uma diversidade de fontes e locais com fronteiras inconstantes" ${ }^{\prime 9}$ e marcos assimétricos.

O Equador ${ }^{50}$ declarou que a unidade do Estado reside na diversidade, e figuram como sujeitos de direitos todas as "[...] personas, comunidades, pueblos, nacionalidades y colectivos [...]" (artigo 10). Prevê, expressamente, que "los derechos serán plenamente justiciables. No podrá alegarse falta de norma jurídica para justificar su violación o desconocimiento, para desechar la acción por esos hechos ni para negar su reconocimiento" ${ }^{51}$ (artigo 11.3), como forma de refutar oposição à legitimidade dos sujeitos de demandarem seus direitos. ${ }^{52}$

Com os Derechos de las comunidades, pueblos y nacionalidades, ampliou-se a titularidade dos direitos coletivos, pelo que "las comunidades, pueblos, y nacionalidades indígenas, el pueblo afroecuatoriano, el pueblo montubio y las comunas forman parte del Estado ecuatoriano, único e indivisible" (artigo 56). Na Función Judicial y justicia indígena, a autonomia indígena baseia-se em tradições próprias, cuja responsabilidade de garantir o respeito às decisões indígenas incumbe ao Estado (artigo 171), o que, para Bello, reflete o pluralismo jurídico, “[...] quando se permite o exercício das funções jurisdicionais pelos povos indígenas com base em suas tradições e no seu 'direito próprio" ${ }^{53}$.

Autonomia municipal (artigos 283 a 284), Órganos ejecutivos de los gobiernos autónomos (artigos 285 a 286), Órganos legislativos, deliberativos y fiscalizadores de los gobiernos autónomos (artigos 287 a 288), Autonomía indígena originaria campesina (artigos 289 a 296) e Distribuición de competências (artigos 297 a 305).

45 Vide: artigo 30.I, 5, 7, 15, 17 e 18. VALENÇA, Daniel Araújo. Bolívia: crise de Estado, disputa hegemônica e ressignificação democrática. In: VAL, Eduardo Manuel; BELLO, Enzo. O pensamento pós e descolonial no novo constitucionalismo latino-americano. Caxias do Sul: Educs, 2014. p. 98.

46 Vide artigos: 269.I, 280. I e II, 270, 273, 280.I, 282, 281, 284, 291.I, 289 e 394.

47 RAMÍREZ, Silvina. Sete problemas do novo constitucionalismo indigenista. In: VERDUM, Ricardo. Povos indígenas: Constituições e reformas políticas na América Latina. Brasília: Instituto de Estudos Socioeconômicos, 2009. p. 220.

48 LEONEL JÚNIOR, Gladstone. O novo constitucionalismo latino-americano: um estudo sobre a Bolívia. 2. ed. Rio de Janeiro: Lumen Juris, 2018. p. 92.

49 SANTOS, Boaventura de Sousa. Reconhecer para libertar: os caminhos do cosmopolitismo multicultural. Civilização brasileira, 2003. p. 468.

50 São expoentes do pluralismo jurídico na Constituição Equatoriana os Princípios fundamentales (Título I, Elementos Constitutivos del Estado); os Principios de aplicación de los derechos e os Derechos de las comunidades, pueblos y nacionalidades (Título II, Derechos); as Garantías normativas e Garantias Jurisdicionales (Título III, Garantias Constitucionales) e a Función Judicial y justicia indigena (Título IV, Participación y Organización del Poder).

51 Vide artigos: 11 e 86.

52 Vide artigos: 98 e 99.

53 BELLO, Enzo. A Cidadania no Constitucionalismo Latino-Americano. Caxias do Sul: EDUCS, 2012. p. 120. 
A Bolívia ${ }^{54}$ tem, como fins e funções essenciais, "[...] garantizar el cumplimiento de los principios, valores, derechos y deberes reconocidos y consagrados en esta Constitución” (artigo 9.4). Também, promover, proteger e respeitar os direitos, sua inviolabilidade, universalidade, interdependência, indivisibilidade e progressividade. Assegura que todo ser humano, sem distinção ou discriminação, possui personalidade e capacidade jurídica, e a todas as pessoas e coletividades, o livre e eficaz exercício de seus direitos. ${ }^{55}$

Os Derechos de las Naciones y Pueblos Indígena Originario Campesino concebem os direitos coletivos como marco da unidade estatal, assegurando às nações e povos indígenas direitos de identidade, territoriais, formas próprias de organização social, educacionais, de representação, consultivas, de cooperação e comunicação. Uma das jurisdições é a indígena originaria campesina, fundamentada "[...] en un vínculo particular de las personas que son miembros de la respectiva nación o pueblo indígena originario campesino" (artigo 191.I). As autoridades indígenas exercem as funções jurisdicionais (artigo 190), e suas decisões devem ser respeitadas pelas demais autoridades públicas. Bello destaca que a estrutura judicial indígena é própria e independente, "[...] uma dentre as formas de tutela judicial dos novos direitos de cidadania", administrada pelos povos, em seus territórios, com normas, procedimentos e autoridades próprios.

O pluralismo econômico é lastreado por inéditos conteúdos constitucionais, diversos dos liberais, como as cosmovisões Sumak Kansay (buen vivir) no Equador e Suma Qamaña (vivir bien) na Bolívia, em harmonia com a Pacha Mama/Pachamama ${ }^{56}$, referências do modelo constitucional plurinacional. Desenvolvimento e progresso são termos sem equivalência em línguas indígenas, reflexos do "[...] sentido moderno occidental de crecimiento en un sentido de posesión de bienes materiales" ${ }^{\text {57 }}$. Por esse motivo, Ascarrunz explica que as Constituições Plurinacionais contêm expressões com

[...] sentidos que denotaban un ideal de vida que no escinde al hombre y a la naturaleza por un lado, y que entre la vida material de la reproducción, la producción y la vida social y espiritual existe una interconexión inseparable, por otro. Hombre/mujer y naturaleza son parte de la Madre Tierra y entre ambos se establece una comunión y un diálogo mediado por una ritualidad que entiende a la Naturaleza como un ser sagrado..$^{58}$

Preambularmente, os Estados Plurinacionais afirmaram suas cosmovisões e as declararam como marco orientador. O Equador ${ }^{59}$ celebrou "[...] la naturaleza, la Pacha Mama, de la que somos parte y que es vital para nuestra existência" e decidiu construir "una nueva forma de convivencia ciudadana, en diversidad y armonía con la naturaleza, para alcanzar el buen vivir, el sumak kawsay". A Bolívia ${ }^{60}$ declarou base no respeito, igualdade, e elencou princípios de “[...] búsqueda del vivir bien; con respeto a la pluralidad económica,

\footnotetext{
54 São expoentes do pluralismo jurídico na Constituição Boliviana, na Primera Parte: Bases fundamentales del Estado, derechos, deberes y garantías Título I, Bases Fundamentales del Estado, os Princípios, valores y fines del Estado (artigos $7^{\circ}$ a 10); Título II, Derechos Fundamentales y Garantías, as Disposiciones generales (artigos 13 e 14), os Derechos fundamentales (artigos 15 a 20), os Derechos civiles (artigos 21 a 25), e os Derechos de las Naciones y Pueblos Indígena Originario Campesino (artigos 30 a 32); Título IV, Garantías jurisdiccionales y acciones de defensa, as Garantias jurisdiccionales (artigo 109 a 124). Segunda parte: Estructura y organización funcional del Estado, Título III, Órgano judicial y Tribunal Constitucional Plurinacional, as Disposiciones generales (artigos 178 ao 179), a Juridición indígena originaria campesina (artigos 190 a 192) e o Tribunal Constitucional Plurinacional (artigos 196 a 204).

55 Vide artigos: 13, 14.I, II e III e 24.

56 Variações linguísticas equatorianas e bolivianas.

57 ASCARRUNZ, Beatriz. El Vivir Bien como sentido y orientacion de políticas públicas. In: FARAH, Ivonne; VASAPOLLO, Luciano. Vivir bien: ¿Paradigma no capitalista? La Paz: Cides-Umsa, 2011. p. 423-438.

58 ASCARRUNZ, Beatriz. El Vivir Bien como sentido y orientacion de políticas públicas. In: FARAH, Ivonne; VASAPOLLO, Luciano. Vivir bien: ¿Paradigma no capitalista? La Paz: Cides-Umsa, 2011. p. 424.

59 Inseridos no Título I, Elementos Constitutivos del Estado, os Princípios fundamentales (artigo $3^{\circ}$ ); Título II, Derechos, os Derechos del Buen Vivir (artigos 12 e 34); Título VI, Regímen de Desarrollo, Principios generales (artigos 275 a 278) e Soberanía económica (artigos 283 a 284); Trabajo y Producción (artigos 319 a 320), no que tange às Formas de organización de la producción y su gestión e Título VII, Regímen del Buen Vivir, a Inclusión y equidad (artigos 340 a 394).

${ }^{60}$ Inseridos, na Primera Parte, Título I, Bases Fundamentales del Estado, os Princípios, valores y fines del Estado (artigos $3^{\circ}$ a 10); Título II, Derechos fundamentales y garantías, os Derechos de las naciones y pueblos indígena originário campesinos (artigos 30 e 32) e Derechos sociales y económicos (artigos 33 ao 107); Cuarta Parte, Título I, Organización económica del Estado, as Disposiciones generales (artigos 306 a 315), a Función del Estado en la economia (artigos 316 a 317), Educación, interculturalidad y derechos culturales (artigos 77 a 105) e Comunicación social (artigos 106 a 107).
} 
social, jurídica, política y cultural de los habitantes de esta tierra; en convivencia colectiva con acceso al agua, trabajo, educación, salud y vivienda para todos".

O régimen de desarrollo do Equador está estruturado no "[...] conjunto organizado, sostenible y dinámico de los sistemas económicos, políticos, socio-culturales y ambientales, que garantizan la realización del buen vivir, del sumak kawsay" (artigo 275). Os Derechos de las naciones y pueblos indígena originário campesinos da Bolívia pautam-se no vivir bien, referendado nas identidades, idiomas, culturas, tradições, instituições, territorialidades e cosmovisões das coletividades humanas, das nações e povos indígenas anteriores à invasão (artigo 30. I), o que, para Wolkmer et al., projetou “[...] uma compreensão da comunidade em harmonia, respeito e equilíbrio com todas as formas de vida" ${ }^{61}$.

O pluralismo de sujeitos, que contempla a Natureza, também se pauta nos elementos, acima apontados, “[...] con la concreción de los Derechos de la Naturaleza en Ecuador o con la aplicación de la Ley de los Derechos de la Madre Tierra en Bolivia" ${ }^{2}$, consoante Santos e Jiménez. A cooperação entre os habitantes, que usufruem o mesmo meio, enseja o foco na Natureza e aos elementos a ela relacionados, de modo que “[...] não é somente uma extensão do direito humano à natureza, mas um direito original, dando a esta personalidade jurídica" ${ }^{63}$, como explica Rodrigues.

O Equador ${ }^{64}$ elencou, como princípio de aplicação dos direitos, que “[...] la naturaleza será sujeto de aquellos derechos que le reconozca la Constitución" (artigo 14), e que "la naturaleza o Pacha Mama, donde se reproduce y realiza la vida, tiene derecho a que se respete integralmente su existencia y el mantenimiento y regeneración de sus ciclos vitales, estructura, funciones y procesos evolutivos" (artigo 71). A Bolívia ${ }^{65}$, preambularmente, declarou a sua refundação sob “[...] la fortaleza de nuestra Pachamama y gracias a Dios”, e relacionou, como fins e funções essenciais, a "[...] conservación del medio ambiente, para el bienestar de las generaciones actuales y futuras" (artigo 9), elementar para que indivíduos, coletividades e outros seres vivos se desenvolvam, normal e permanente. ${ }^{66}$

Para Santos e Jiménez, ambas as Constituições, ao compartilharem das cosmovisões de Sumak Kawsay e Suma Qamaña, se estabelecem sobre conceitos de equilíbrio e harmonia, em "[...] una dimensión que va más allá de la propia comunidad, en sentido estricto, y más allá de las dimensiones 'terrenales' de la realidad, incluyendo a la propia Pachamama o si se prefere a una dimensión supranatural”' ${ }^{37}$. A interculturalidade, a plurinacionalidade e o pluralismo, pois, conceituados e enumerados, enquanto elementos fundantes dos Textos constitucionais, podem ser apontados como princípios norteadores do Estado Plurinacional e como

\footnotetext{
61 WOLKMER, Antonio Carlos; AUGUSTIN, Sergio; WOLKMER, Maria de Fátima S. O "Novo" Direito à Água no Constitucionalismo da América Latina. Revista Internacional Interdisciplinar Interthesis, Florianópolis, v. 9, n. 1, jan./jun. 2012. p. 56.

62 SANTOS, Boaventura de Sousa; JIMÉNEZ, Agustín Grijalva (Ed.). Justicia indígena, plurinacionalidad e interculturalidad en Bolivia. Quito: Fundación Rosa Luxemburg, 2012. p. 32.

63 RODRIGUES, Isabel Nader. Recursos naturais na sociedade capitalista e o paradigma do Sumak Kawsay. In: VAL, Eduardo Manuel; BELLO, Enzo. O pensamento pós e descolonial no novo constitucionalismo latino-americano. Caxias do Sul: Educs, p. 148-165, 2014, p. 159.

${ }^{64}$ Como expoentes constitucionais: inseridos no Título I, Elementos Constitutivos del Estado, os Princípios fundamentales (artigo $1^{\circ}$ ); Título II, Derechos, os Derechos del Buen Vivir (artigo 14) e Derechos de la naturaleza (artigos 71 a 74), Título VI, Regímen de Desarrollo, Principios generales (artigos 275 a 278) e Soberanía económica (artigos 283 a 284); Título VII, Regímen del Buen Vivir, a Biodiversidad y recursos naturales (artigos 395 a 415).

65 Como expoentes constitucionais: inseridos no Título I, Bases Fundamentales del Estado, os Princípios, valores y fines del Estado (artigo $9^{\circ}$ ); no Título II, Derechos fundamentales y garantías, Capítulo 5, Derechos sociales y económicos, e a Seção Derecho ao medio ambiente (artigos 33 e 34) Segunda Parte, Título III, Órgano judicial y Tribunal Constitucional Plurinacional, a Jurisdicción agroambiental (artigos 186 a 189) Cuarta Parte, Título I, Organización económica del Estado, a Función del Estado na economia (artigos 316 a 317), Título II, Medio ambiente, recursos naturales, tierra y território, Medio ambiente (342 a 347), Recursos naturales (artigos 348 a 358), Hidrocarburos (artigos 359 a 368), Mineria y metalurgia (artigos 369 a 372), Recursos hídricos (artigos 373 a 377), Energia (artigos 378 e 379), Biodiversidad, coca, aresas protegidas y recursos florestales (artigos 380 a 389), Amazonia (artigos 390 a 392) e Tierra y território (artigos 393 a 404), Título III, Desarrollo rural integral sustentable (artigos 405 a 409).

${ }^{66}$ Vide artigos: 298.5, 6 e 7, 33, 99, 108.14, 15 e 16 e 124.I.2.

67 SANTOS, Boaventura de Sousa; JIMÉNEZ, Agustín Grijalva (Ed.). Justicia indígena, plurinacionalidad e interculturalidad en Bolivia. Quito: Fundación Rosa Luxemburg, 2012. p. 88.
} 
supedâneos inéditos para a afirmação de um modelo de constitucionalismo convergente com os povos e grupos, que são, ao mesmo tempo, constituintes e sujeitos de direitos.

\section{Interculturalidade, pluralidade e pluralismo como princípios constitucionais do Estado Plurinacional}

Os sujeitos coletivos descoloniais estabeleceram os marcos epistemológicos do próprio Estado, pela reivindicação de uma estrutura constitucional que fosse condizente com a realidade social, em substituição ao modelo europeu/nortista, importado e imposto pelos colonizadores. A matriz descolonial representa a visão crítica sobre o universalismo ocidental, em que "o grito e o pranto gradualmente se tornam uma atitude crítica, cognitiva e prática que se pode chamar 'atitude descolonial”" ${ }^{8}$, como destaca Maldonado-Torres.

Os rearranjos estruturais, no Equador (2008) e na Bolívia (2009), representam a conjunção dos atores sociais, por intermédio da interculturalidade, da pluralidade e do pluralismo, elevando suas reivindicações ao nível constitucional, e, a partir daí, pautando-se nos textos constitucionais, "[...] agora destituídos da pompa jurídica elitista" ${ }^{69}$, nas palavras de Leonel Júnior, para avançar na garantia de seus direitos.

Como exemplos dos princípios ancestrais, a Constituição Boliviana exortou a ama qhilla, ama llulla, ama suwa; suma qamaña, ñandereko; tekokavi; ivimaraei e qhapajnan ${ }^{70}$ (artigo 8.I), linguagem que substitui termos modernos, mas, também, em Latim, como habeas corpus e habeas data, para Acción de Libertad e Acción de Protección de Privacidad". Santos e Jiménez destacam que os povos recuperaram "[...] la soberanía como único titular, que la ejerce de manera directa, delegada o bajo normas y procedimientos propios" ${ }^{\text {"72, }}$, o que perpassou pela inserção de princípios constitucionais, igualmente, próprios.

Nesse aspecto, a interculturalidade, que pautou a condução da refundação estatal, se expressa na ideia de enfrentamento e "[...] reforma de las condiciones de no correspondencia entre estado y multiculturalidad" 73 , como pontua Tápia. Para atender à diversidade cultural, às formas de governo próprias e as ordens econômicas sustentáveis, foi necessário "[...] no sólo cambiar los sujetos gobernantes sino también la forma del gobierno y el conjunto de las instituciones" "74. Tais alterações foram possíveis pelo protagonismo e diálogo intercultural dos povos indígenas e movimentos descoloniais, pois, como destaca Santos, "[...] tiene que articularse con otros grupos, tiene que saber salir de sí mismo y entrar en diálogo con otros grupos sociales bastante heterogéneos" $"$.

Os movimentos desvelaram, nas palavras de Mignolo e Walsh, "[...] legados vividos e longos horizontes de dominação, opressão, exclusão e diferença colonial (ontológica, política, econômica, cultural, epistêmica, cosmológica e baseada na existência)" "ᄁ6, e a visão crítica da interculturalidade exigiu "[...] uma mudança radical na ordem dominante e em sua base fundacional do capitalismo, da modernidade ocidental e do poder

\footnotetext{
68 MALDONADO-TORRES, Nelson. Pensamento crítico desde a subalteridade: os Estudos Étnicos como ciências descoloniais ou para a transformação das humanidades e das ciências sociais no século XXI. Afro-Ásia, n. 34, 2017. p. 126.

69 LEONEL JÚNIOR, Gladstone. O novo constitucionalismo latino-americano: um estudo sobre a Bolívia. 2. ed. Rio de Janeiro: Lumen Juris, 2018, p. 91.

70 No seas fojo, no seas mentiroso, no seas ladrón; Vida harmoniosa; Vida buena; Tierra sin mal; Camino o vida noble.

71 Artigos 125 e 130 e seguintes, respectivamente.

72 SANTOS, Boaventura de Sousa; JIMÉNEZ, Agustín Grijalva (Ed.). Justicia indígena, plurinacionalidad e interculturalidad en Bolivia. Quito: Fundación Rosa Luxemburg, 2012. p. 384.

73 TAPIA, Luis. Una reflexión sobre la idea de Estado plurinacional. Osal, v. 8, n. 22, p. 47-63, 2007. p. 52.

74 TAPIA, Luis. Una reflexión sobre la idea de Estado plurinacional. Osal, v. 8, n. 22, p. 47-63, 2007. p. 52.

75 SANTOS, Boaventura de Sousa. Pensar el Estado y la sociedad: desafíos actuales. Buenos Aires: Waldhuter, 2009. p. 29.

76 Texto original: "[...] visible lived legacies and long horizons of domination, oppression, exclusion, and colonial difference (ontological, political, economic, cultural, epistemic, cosmological, and existence based)". MIGNOLO, Walter; WALSH, Catherine. On decoloniality: concepts, analytics, práxis. Durham: Duke University Press, 2018. p. 58.
} 
colonial em curso" $" 77$.

No lugar das uniformidades e monismos, foram estabelecidas nacionalidades e diversidades políticas, culturais, religiosas, linguísticas e territoriais, de modo que, segundo Santos, o resultado foi um "[...] combinar diferentes conceptos de nación dentro de un mismo Estado" ${ }^{78}$. A interculturalidade se constitui como novidade na teoria política ao insculpir, nas Constituições do Equador e da Bolívia, o "[...] mandato directo del poder constituyente y, en consecuencia, fundamento último de la razón de ser del poder constituído"79, nas palavras de Dalmau e Pastor.

Nesse paradigma, a plurinacionalidade corresponde a identidades coletivas conscientes, auto-organizáveis, autodetermináveis ${ }^{80}$, interligadas pelas movimentações sociopolíticas que culminaram no constitucionalismo desde abajo, "[...] protagonizado por los excluidos y sus aliados, com el objetivo de expandir el campo de lo político más allá del horizonte liberal" ", como aponta Santos. A unificação política das matrizes sociais conduziu o entrar en un Estado plurinaciona ${ }^{22}$, resultando no fortalecimento do próprio Estado, ancorado, como aponta Albó, no "[...] pluralismo social y cultural de los pueblos originarios y ser utilizada para garantizar el propio desarrollo de cada pueblo en vez de irlos diluyendo em un 'estado mestizo' uniformante" ${ }^{\text {" }}$.

Tápia aponta que o novo modelo político resultou na introdução da “[...] plurinacionalidad en el formato

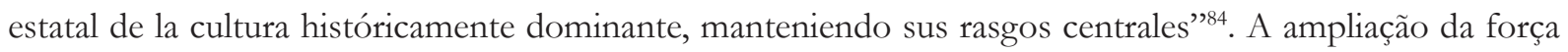
social da Constituição decorre da plurinacionalidade contramajoritária ${ }^{85}$, que afastou o reducionismo de textos nominais, produzidos e por/para elites, e fez, nas palavras de Pastor e Dalmau, ressurgir a constatação, “[...] no sólo teórica sino principalmente empírica, de que el constitucionalismo como proceso político de transformación social conforma Constituciones adecuadas a la fuerza con que aquél emerge" ${ }^{86}$.

A interculturalidade, enquanto cultura contrapartida, que representa "[...] la manera específica en que cada sociedad organiza su plurinacionalidad, su convivencia plurinacional" ${ }^{17}$, e a plurinacionalidade como expressão da responsabilidade estatal em assegurar a convivência intercultural, em "[...] buscar formas de unificación sin uniformidad; una geometría variable del Estado" ${ }^{88}$, nas palavras de Santos, correlacionam-se.

O fortalecimento dos direitos coletivos depende da participação dialógica dos sujeitos, pois, segundo Grijalva, "[...] as limitações ao desenvolvimento da plurinacionalidade e da interculturalidade advêm mais da dinâmica de forças políticas e econômicas do que de particularidades das normas formalmente vigentes" ${ }^{89}$. Insere-se, nesse aspecto, o princípio da solidariedade, implícito nas cosmovisões que alicerçam o Estado

\footnotetext{
77 Texto original: "[...] calls for radical change in the dominant order and in its foundational base of capitalism, Western modernity, and ongoing colonial power". MIGNOLO; WALSH, op cit. p. 58.

78 SANTOS, op. cit., p. 202.

79 DALMAU, Rubén Martínez. PASTOR, Roberto Viciano. Fundamento teórico del nuevo constitucionalismo latinoamericano. In: PASTOR, Roberto Viciano. (Ed.). Estudios sobre el nuevo Constitucionalismo Latinoamericano. Valencia: Tirant lo Blanch, p. 11-50, 2012, p. 20.

80 WOLKMER, Antonio Carlos. Pluralismo Jurídico. Fundamentos de uma nova cultura do Direito. 4. ed. São Paulo: Saraiva, 2015. Disponível em: https://books.google.com.br/books?isbn=8502228366. Acesso em: 10 Abr. 2021.

81 SANTOS, Boaventura. Refundación del Estado en América Latina: perspectivas desde una epistemología del Sur. La Paz: Plural, 2010 , p. 72.

82 SANTOS, Boaventura. Refundación del Estado en América Latina: perspectivas desde una epistemología del Sur. La Paz: Plural, 2010 , p. 52.

83 ALBÓ, Xavier. Movimientos y poder indígena en Bolivia, Ecuador y Perú. La Paz: Cipca, 2008. p. 54.

84 TAPIA, Luis. Una reflexión sobre la idea de Estado plurinacional. Osal, v. 8, n. 22, p. 47-63, 2007. p. 62.

85 WOLKMER, Antonio Carlos. Pluralismo Jurídico. Fundamentos de uma nova cultura do Direito. 4. ed. São Paulo: Saraiva, 2015. Disponível em: https://books.google.com.br/books?isbn=8502228366. Acesso em: 10 Abr. 2021.

86 PASTOR, Roberto Viciano; DALMAU, Rubén Martínez. Los procesos constituyentes latinoamericanos y el nuevo paradigma constitucional. IUS. Revista del Instituto de Ciencias Jurídicas de Puebla AC, n. 25, 2010. p. 9.

87 SANTOS, Boaventura de Sousa. Pensar el Estado y la sociedad: desafíos actuales. Buenos Aires: Waldhuter Editores, 2009 , p. 203.

88 SANTOS, Boaventura de Sousa. Pensar el Estado y la sociedad: desafíos actuales. Buenos Aires: Waldhuter Editores, 2009 , p. 204.

89 GRIJALVA, Agustín. O Estado plurinacional e intercultural na Constituição equatoriana de 2008. In: VERDUM, Ricardo. Povos indígenas: Constituições e reformas políticas na América Latina. Brasília: Instituto de Estudos Socioeconômicos, p. 113-134, 2009, p. 129.
} 
Plurinacional, para, conforme Sánchez, “[...] corrigir os desequilíbrios ou as desigualdades econômicas inter-territoriais e impedir o estabelecimento de privilégios econômicos em favor de alguma entidade territorial autônoma" $"$.

Por sua vez, o pluralismo reflete o questionamento da naturalização hierárquica, contida nos antigos Textos Constitucionais, uma vez que a Constituição Plurinacional Equatoriana e Boliviana, respectivamente, rechaça as "[...] formas de dominación y colonialismo", e afirma que "[...] jamás comprendimos el racismo hasta que lo sufrimos desde los funestos tiempos de la colônia". O pluralismo político situa-se na expressão dos sujeitos coletivos enquanto sujeitos políticos, desde sua exterioridade, e contrapôs, segundo Leonel Júnior, os "[...] marcos teóricos e modelos políticos que não os levavam em conta, ganharam reconhecimento a partir das lutas sociais e inspiram uma série de transformações institucionais"»1.

Maldonado-Torres aponta a multiplicidade dos sujeitos, seus conhecimentos, experiências e modos de vida, como "[...] altamente relevantes para entender las formas modernas de poder y para proveer alternativas a las mismas" "92, que comportam o princípio do pluralismo, em seus diversos vieses. Aponta-se, como exemplo, o uso de línguas originárias como termos constitucionais, apropriados para apontar os conceitos e objetivos que os povos e nações pretendiam para o Estado.

O pluralismo jurídico evidencia-se no Pluralismo Jurídico Igualitário, que possui, como expoente, o Tribunal Constitucional Plurinacional boliviano, de formação democrática ${ }^{93}$, intercultural, e último reduto decisório. A partir dos Textos dos Estados Plurinacionais, Dantas destaca a importância de "[...] os mesmos setores que se organizaram e mobilizaram para a criação dessas Constituições continuem mobilizados para que haja a efetivação e concretização desses postulados constitucionais". ${ }^{94}$

Exorta-se, também, a coexistência democrática de nações ou nacionalidades sob o marco do mesmo Estado, porque a diversidade plurinacional reconhece a legitimidade das formas de organização, ação política, gestão territorial e econômica. Como resultados do pluralismo jurídico no Equador e na Bolívia, os povos indígenas detêm, segundo Fajardo:

a) la potestad de darse sus normas; b) Sus propias autoridades/autoridades de las comunidades, pueblos y nacionalidades indígenas; c) Funciones jurisdiccionales. [...] El derecho al propio derecho o el sistema jurídico indígena, a sus normas y procedimientos propios, costumbres, usos, etc. [...] Ejercicio del sistema jurídico de acuerdo a su cosmovisión. ${ }^{95}$

Juridicamente, as Constituições Plurinacionais são híbridos jurídicos, ou seja, comportam o rearranjo do poder ${ }^{96}$ sob o marco da cosmovisão indígena, que "[...] se traduce en nuevos derechos sociales que incorporan la perspectiva indígena, como el derecho al agua, al 'buen vivir' y a la seguridad alimentaria, entre otros"97.

\footnotetext{
90 SÁNCHEZ, Consuelo. Autonomia, Estados Pluriétnicos e Plurinacionais. In: VERDUM, Ricardo. Povos indígenas: Constituições e reformas políticas na América Latina. Brasília: Instituto de Estudos Socioeconômicos, p. 63-90, 2009. p. 83.

91 LEONEL JÚNIOR, Gladstone. O novo constitucionalismo latino-americano: um estudo sobre a Bolívia. 2. ed. Rio de Janeiro: Lumen Juris, 2018. p. 55.

92 MALDONADO-TORRES, Nelson. La descolonización y el giro des-colonial. Tabula rasa, n. 9, 2008. p. 66.

93 Artigo 197.I.

94 DANTAS, Fernando Antônio de Carvalho. Entre a nação imaginada e o Estado Plurinacional: o reconhecimento dos direitos indígenas no novo constitucionalismo latino americano. In: AVRITZER, Leonardo; GOMES, Lilian Cristina Bernardo; MARONA, Marjorie Corrêa; DANTAS, Fernando Antônio de Carvalho. O constitucionalismo democrático latino-americano em debate. Belo Horizonte: Autêntica, p. 213-230, 2017.

95 FAJARDO, Raquel Z. Yrigoyen. El horizonte del constitucionalismo pluralista: del multiculturalismo a la descolonización. In: GARAVITO, César Rodríguez (Coord.). El derecho en América Latina: um mapa para el pensamento jurídico del siglo XXI. Buenos Aires: Siglo Veinteuno, p. 139-160, 2011. p. 150. Vide artigos: 171 e a seção sobre Justicia Indígena (Equador) e artigos $30 . I I .14$ e 190 e o Capítulo IV Jurisdicción indigena originaria campesina (Bolívia).

96 SANTOS, Boaventura de Sousa; JIMÉNEZ, Agustín Grijalva (Ed.). Justicia indígena, plurinacionalidad e interculturalidad en Bolivia. Quito: Fundación Rosa Luxemburg, 2012.

97 FAJARDO, Raquel Z. Yrigoyen. El horizonte del constitucionalismo pluralista: del multiculturalismo a la descolonización. In: GARAVITO, César Rodríguez (Coord.). El derecho en América Latina: um mapa para el pensamento jurídico del siglo XXI. Buenos Aires: Siglo Veinteuno, p. 139-160, 2011. p. 149.
} 
A multiplicidade de jurisdições denuncia o simplismo do monismo jurídico, fortalece o exercício da justiça, por refletir a interculturalidade das percepções sobre direitos, justiças e administrações por "[...] uma perspectiva normativa insurgente e societária que pleiteia a supremacia de fundamentos ético-político-sociológicos sobre critérios centralizadores tecnoformais positivistas" ${ }^{" 1}$. A justiça indígena é anterior e independente do reconhecimento estatal, e, para Rodríguez et al., "[...] constituyen testimonios de que otro mundo es posible, otra lógica de convivencialidad y de organización social que se ha plasmado en los últimos años en los conceptos de Sumak Kawsay o Suma Qamaña, el Buen Vivir"’9.

O pluralismo econômico está insculpido nos princípios ancestrais do Sumak Kawsay e do Suma Qamaña, que transversalizam as Constituições e significam vida boa, na interrelação ou correlação harmoniosa de e entre todos os seres. Reflete na "[...] água e comida, cultura e ciência, educação, habitação e habitat, saúde, trabalho, comunidade, natureza, território e terra, economia, direitos individuais e coletivos, entre outras áreas de interrelação" ${ }^{100}$, conforme Mignolo e Walsh.

As cosmovisões asseguram a participação legítima dos expoentes sociais nos espaços de decisão e em oposição à visão antropocêntrica e ao sistema capitalista, posto que, para Farah e Vasapollo, “[...] no es posible ignorar los efectos de los patrones actuales de desarrollo, ya que su naturaleza y profundidad amenazan la vida en el mundo"101. Sociedades, natureza e vida democrática se relacionam e reorganizam o Estado, pois, para Sánchez, "[...] em relação ao mundo liberal, o indígena pressupõe o enfrentamento de suas formas de ver e estar no mundo. Aí reside sua transcendência" ${ }^{102}$.

Por fim, o pluralismo de sujeitos conjura os demais pluralismos, já que a Pachamama, onde a vida se materializa e se reproduz, é a Mãe Natureza, conceituada, por Mignolo e Walsh, como “[...] um ser vivo com inteligência, sentimentos e espiritualidade dos quais os humanos fazem parte. É uma composição de intersubjetividade, de seres em relação" 103 , lógica que supera a percepção de objeto, usado, controlado e dominado. Desconsiderar a Pacha Mama/Pachamama significa macular o direito de existência dos seres, inclusive, dos humanos, com valor ontológico, “[...] punto medular de los derechos de la naturaleza, destacando una relación estructural y complementaria con los derechos humanos" ${ }^{104}$. O cenário intercultural refletiu valores ou direitos elevados, constitucionalmente, em que "[...] los derechos de la Madre Tierra entran precisamente en ese orden de cosas" ${ }^{\prime 105}$.

A par das considerações, mesmo em análise teórica, pode-se afirmar que as alterações jurídicas, estampadas nas configurações constitucionais do Equador e da Bolívia, apresentam elementos inéditos, que perpassam a singularidade dos países e indicam traços fundamentais do Estado Plurinacional. Esse modelo de Estado avaliza práticas políticas emancipatórias e convergentes com as realidades dos grupos e nações formadores, arranjo em que a carga principiológica inovadora lastreada, conforme Martínez, é “[...] forte, original, e vinculante, necesaria nunhas sociedades que confiaron na mudanza constitucional a possibilidade

\footnotetext{
98 WOLKMER, Antonio Carlos. Pluralismo Jurídico. Fundamentos de uma nova cultura do Direito. $4^{a}$ ed. São Paulo: Saraiva, 2015. p. 13. Disponível em: https://books.google.com.br/books?isbn=8502228366. Acesso em: 10 Abr. 2021.

99 RODRÍGUEZ, Paulo; MANZANO, Tania Arias; UMPIERREZ, Fernando Yávar. Constitucionalismo ecuatoriano: la plurinacionalidad y la ecologia constitucional. In: SANTOS, Boaventura de Sousa. Cuando los excluidos tienen derecho: justicia indígena, plurinacionalidad e interculturalidade. Quito: Fundación Rosa Luxemburg, p. 9-14, 2012, p. 8.

100 Texto original: "[...] water and food, culture and science, education, housing and habitat, health, work, community, nature, territory and land, economy, and individual and collective rights, among other areas of interrelation”. Ibid., p. 64.

101 FARAH, Ivonne; VASAPOLLO, Luciano. Vivir bien:̨̇ Paradigma no capitalista? La Paz: Cides-Umsa, 2011, p. 11.

102 SÁNCHEZ, Consuelo. Autonomia, Estados Pluriétnicos e Plurinacionais. In: VERDUM, Ricardo. Povos indígenas: Constituições e reformas políticas na América Latina. Brasília: Instituto de Estudos Socioeconômicos, p. 63-90, 2009. p. 83.

103 Texto original: "[...] a living being with intelligence, feelings, and spirituality of which humans are part. It is a compositive of intersubjectivity, of beings in relation". MIGNOLO, Walter; WALSH, Catherine. On decoloniality: concepts, analytics, práxis. Durham: Duke University Press, 2018. p. 65.

104 SANTOS, Boaventura de Sousa; JIMÉNEZ, Agustín Grijalva (Ed.). Justicia indígena, plurinacionalidad e interculturalidad en Bolivia. Quito: Fundación Rosa Luxemburg, 2012. p. 173.

105 SANTOS, Boaventura de Sousa; JIMÉNEZ, Agustín Grijalva (Ed.). Justicia indígena, plurinacionalidad e interculturalidad en Bolivia. Quito: Fundación Rosa Luxemburg, 2012. p. 141.
} 
dunha verdadeira revolución"106.

As Constituições Plurinacionais institucionalizaram a desocidentalização epistêmica, a descolonização do poder e da própria ideia de sociedade civil, porque os sujeitos, antes marginalizados e passivos, avançaram para sujeitos ativos, constituintes e protagonistas de um Estado dos quais possam avocar identidade, pertencimento e legitimidade. As Constituições do Equador e da Bolívia são instrumentos jurídicos do giro descolonial, que visam, nas palavras de Médici, “[...] decuar la constitución jurídica formal a la compleja realidad socio económica y cultural de dichas sociedades, a sus necesidades y aspiraciones de justicia y transformación, sin renunciar a sus pertenencias culturales" ${ }^{107}$. A inserção e a exaltação de novos princípios constitucionais, destacadamente, da interculturalidade, da plurinacionalidade e do pluralismo, contribuem, ao menos, formalmente, para ressignificar a teoria do Estado desde el Sur.

\section{Considerações finais}

O constitucionalismo latino-americano, nos expoentes da Constitución de la República del Ecuador, de 2008, e na Constitución Politica del Estado da Bolívia, de 2009, inaugurou uma institucionalidade reflexiva das demandas sociais, e, portanto, com maior legitimidade e capacidade integradora, em comparação às antigas Constituições, sob o prisma eurocêntrico. As Constituições foram elaboradas por meio de Assembleias Constituintes e com ampla participação dos setores populares, aproximando-se das realidades sociais, porque estas foram refletidas em seu Texto pelas concepções da interculturalidade, da plurinacionalidade e dos pluralismos, neste Artigo, apontados como princípios constitucionais.

Elevar as cosmovisões dos povos, que constituem o Estado, ao seu Documento fundacional, representa o questionamento da estrutura, até então, imposta, e transcende o próprio Estado, porque, como destacam Mignolo e Walsh, "seu conceito, proposição e razão estão no esforço mais amplo de descolonização"108. Os princípios constitucionais, propostos neste artigo, são precursores do projeto descolonizador, pois, “juntos, a plurinacionalidade e a interculturalidade têm sido elementos constitutivos da insurgência e da prática decolonial[...]"109.

Conclui-se, pois, que as demandas dos movimentos indígenas e setores marginalizados conduziram o repensar e a refundação do Estado, elevando, a ele, suas cosmovisões, que permeiam os princípios do Estado Plurinacional, refletindo, inclusive, em inovações na teoria constitucional clássica. O significado sociopolítico estampa a interculturalidade; a diversidade, inserta no espaço geopolítico estatal, caracteriza a plurinacionalidade e o rearranjo estatal, nos mais variados campos, como político, jurídico, econômico, cultural, pluralismo educacional, linguístico, comunicativo e de sujeitos, delineiam o pluralismo.

É viável e pertinente debates sobre as inovações constitucionais e teóricas do Estado na contemporaneidade, para além do lócus nortista, este que estava aquém das possibilidades de cosmovisões e da democracia participativa e comunitária, características do Estado Plurinacional. A filosofia jurídica emancipadora do giro descolonial assentou, nas Constituições, uma representatividade transversal dos grupos sociais, inclusive, com um vocabulário representativo de suas buscas e objetivos, como a coexistência, a solidariedade e a

\footnotetext{
106 MARTÍNEZ, Rubén Dalmau. Asembleas constituintes e novo constitucionalismo em América Latina. Tempo Exterior. N. ${ }^{\circ} 17$, p. $5-15,2008$, p. 5.

107 MEDICI, Alejandro. El nuevo constitucionalismo latinoamericano y el giro decolonial: Bolivia y Ecuador. Derecho y Ciencias Sociales, Octubre, nº3. Instituto de Cultura Jurídica y Maestría en Sociología Jurídica. FCJyS.UNLP, 2010. p. 4.

108 Texto original: "[...] the plurinational goes beyond the state itself; its concept, proposition, and reason are in the broader endeavor of decolonization". MIGNOLO; WALSH, op cit., p. 63.

109 Texto original: "Together, plurinacionality and interculturality have been constitutive elements of Ecuador's Indigenous movement’s insurgency and decolonial práxis”. Ibid., p. 63.
} 
alteridade, refletidas no Sumak Kawsay e no Suma Qamaña.

O Estado Plurinacional e seus princípios figuram como um paradigma epistemológico, político e social, que, para Santos, atualmente, pode “[...] não estar definida, mas que tem potencial de impedir que se retorne ao status quo, pela constante problematização, tecida a partir dos projetos constitucionais transformadores, pontos de partida para alterações paradigmáticas e transnacionais de longo prazo" ${ }^{110}$. Como apontado, o Artigo não investigou ou avaliou a efetivação dos princípios da interculturalidade, da plurinacionalidade e do pluralismo, mas visou a abordar, no campo teórico, tais elementos do Estado Plurinacional, seu impacto em conceitos de procedência nortista. Não se desconsideram os processos e movimentos em curso, dadas as ebulições sociais no Equador, na Bolívia e nos demais países da América Latina, de modo que a análise teórica pode contribuir para enfatizar o acerto dos novos arranjos constitucionais descoloniais e a sua força para resistir às investidas da colonialidade.

\section{Referências}

ALBÓ, Xavier. Movimientos y poder indígena en Bolivia, Ecuador y Perú. La Paz: Cipca, 2008.

ALVAR, Manuel. Lengua nacional y sociolinguística: las constituciones de América. Bulletin hispanique, v. 84, n. 3, p. 347-414, 1982.

ASCARRUNZ, Beatriz. El Vivir Bien como sentido y orientacion de políticas públicas. In: FARAH, Ivonne; VASAPOLLO, Luciano. Vivir bien: ¿Paradigma no capitalista? La Paz: Cides-Umsa, 2011, p. 423-438.

BALLESTRIN, Luciana. América Latina e o giro decolonial. Revista brasileira de ciência política, n. 11, p. 89-117, 2013.

BELLO, Enzo. A Cidadania no Constitucionalismo Latino-Americano. Caxias do Sul: EDUCS, 2012.

ESTADO PLURINACIONAL DE BOLIVIA. Constitución politica del Estado. La Paz: Gaceta Oficial del Estado Plurinacional de Bolivia, 2009.

CASANOVA, Pablo González. Colonialismo interno (una redefinición). Colonialismo interno (una redefinición). In: BORON, Atilio A.; AMADEO, Javier; GONZÁLEZ, Sabrina (Comp.). La teoría marxista hoy. Problemas y perspectivas. Buenos Aires, CLACSO, 2006. p. 409-434.

COMPARATO, Fábio Konder. Prefácio. In: FAORO, Raymundo. A República inacabada. São Paulo: Globo, 2007.

CORREA, Rafael. Equador: da noite neoliberal à revolução cidadã. São Paulo: Boitempo, 2015.

DALMAU, Rubén Martínez. PASTOR, Roberto Viciano. Fundamento teórico del nuevo constitucionalismo latinoamericano. In: PASTOR, Roberto Viciano. (Ed.). Estudios sobre el nuevo Constitucionalismo Latinoamericano. Valencia: Tirant lo Blanch, 2012. p. 11-50.

DANTAS, Fernando Antônio de Carvalho. Entre a nação imaginada e o Estado Plurinacional: o reconhecimento dos direitos indígenas no novo constitucionalismo latino americano. In: AVRITZER, Leonardo; GOMES, Lilian Cristina Bernardo; MARONA, Marjorie Corrêa; DANTAS, Fernando Antônio de Carvalho. O constitucionalismo democrático latino-americano em debate. Belo Horizonte: Autêntica, 2017. p. 213-230.

ASAMBLEA CONSTITUYENTE DE ECUADOR\,. Constitución de la República del Ecuador. Quito: Registro Oficial, 2008.

110 SANTOS, Denise Tatiane Girardon dos. Estados Plurinacionais na América Latina: cenários para o republicanismo na contemporaneidade. Curitiba: CRV, 2020. 
FAJARDO, Raquel Z. Yrigoyen. El horizonte del constitucionalismo pluralista: del multiculturalismo a la descolonización. In: GARAVITO, César Rodríguez (Coord.). El derecho en América Latina: um mapa para el pensamento jurídico del siglo XXI. Buenos Aires: Siglo Veinteuno, 2011. p. 139-160.

FARAH, Ivonne; VASAPOLLO, Luciano. Vivir bien:¿ Paradigma no capitalista? La Paz: Cides-Umsa, 2011, p. 11.

GRIJALVA, Agustín. O Estado plurinacional e intercultural na Constituição equatoriana de 2008. In: VERDUM, Ricardo. Povos indígenas: Constituições e reformas políticas na América Latina. Brasilia: Instituto de Estudos Socioeconômicos, 2009. p. 113-134.

LEONEL JÚNIOR, Gladstone. O novo constitucionalismo latino-americano: um estudo sobre a Bolívia. 2. ed. Rio de Janeiro: Lumen Juris, 2018.

LINERA, Álvaro García. A potência plebeia. São Paulo: Boitempo, 2010.

MALDONADO, Ana María Larrea. El movimiento indígena ecuatoriano: participación y resistencia. Observatorio Social de América Latina, v. 5, n. 13, p. 67-76, 2004.

MALDONADO-TORRES, Nelson. La descolonización y el giro des-colonial. Tabula rasa, n. 9, 2008.

MALDONADO-TORRES, Nelson. Pensamento crítico desde a subalteridade: os Estudos Étnicos como ciências descoloniais ou para a transformação das humanidades e das ciências sociais no século XXI. Afro-Ásia, n. 34, 2017.

MARTÍNEZ, Rubén Dalmau. Asembleas constituintes e novo constitucionalismo em América Latina. Tempo Exterior, n. 17, p. 5-15, 2008.

MEDICI, Alejandro. El nuevo constitucionalismo latinoamericano y el giro decolonial: Bolivia y Ecuador. Derecho y Ciencias Sociales, Octubre, n. 3. Instituto de Cultura Jurídica y Maestría en Sociología Jurídica. FCJyS.UNLP, 2010.

MIGNOLO, Walter; WALSH, Catherine. On decoloniality: concepts, analytics, práxis. Durham: Duke University Press, 2018.

PASTOR, Roberto Viciano; DALMAU, Rubén Martínez. Los procesos constituyentes latinoamericanos y el nuevo paradigma constitucional. IUS. Revista del Instituto de Ciencias Jurídicas de Puebla AC, n. 25, 2010.

RAMÍREZ, Silvina. Sete problemas do novo constitucionalismo indigenista. In: VERDUM, Ricardo. Povos indigenas: Constituições e reformas políticas na América Latina. Brasilia: Instituto de Estudos Socioeconômicos, p. 213-235, 2009.

RODRIGUES, Isabel Nader. Recursos naturais na sociedade capitalista e o paradigma do Sumak Kawsay. In: VAL, Eduardo Manuel; BELLO, Enzo. O pensamento pós e descolonial no novo constitucionalismo latino-americano. Caxias do Sul: Educs, 2014. p. 148-165.

RODRÍGUEZ, Paulo; MANZANO, Tania Arias; UMPIERREZ, Fernando Yávar. Constitucionalismo ecuatoriano: la plurinacionalidad y la ecologia constitucional. In: SANTOS, Boaventura de Sousa. Cuando los excluidos tienen derecho: justicia indígena, plurinacionalidad e interculturalidade. Quito: Fundación Rosa Luxemburg, 2012. p. 9-14.

SÁNCHEZ, Consuelo. Autonomia, Estados Pluriétnicos e Plurinacionais. In: VERDUM, Ricardo. Povos indígenas: Constituições e reformas políticas na América Latina. Brasília: Instituto de Estudos Socioeconômicos, 2009. p. 63-90.

SANTOS, Boaventura de Sousa. Pensar el Estado e la sociedad: desafios actuales. Buenos Aires: Waldhuter, 2009.

SANTOS, Boaventura de Sousa. Reconhecer para libertar: os caminhos do cosmopolitismo multicultural. 
Civilização brasileira, 2003.

SANTOS, Boaventura de Sousa; JIMÉNEZ, Agustín Grijalva (eds.). Justicia indígena, plurinacionalidad e interculturalidad en Bolivia. Quito: Fundación Rosa Luxemburg, 2012.

SANTOS, Boaventura. Refundación del Estado en América Latina: perspectivas desde una epistemología del Sur. La Paz: Plural, 2010.

SANTOS, Denise Tatiane Girardon dos. Estados Plurinacionais na América Latina: cenários para o republicanismo na contemporaneidade. Curitiba: CRV, 2020.

SCHAVELZON, Salvador Andrés. As Categorias Abertas da Nova Constituição Boliviana. Formação do Estado Plurinacional: Alguns Percursos Intelectuais. Revista Lugar Comum, n. 27, p. 35 - 60, 2009.

SOUSA, Adriano Corrêa de. A emancipação como objetivo central do novo constitucionalismo latinoamericano: os caminhos para um constitucionalismo da libertação. In: VAL, Eduardo Manuel; BELLO, Enzo. $O$ pensamento pós e descolonial no novo constitucionalismo latino-americano. Caxias do Sul: Educs, 2014. p. 65-86.

VALENÇA, Daniel Araújo. Bolívia: crise de Estado, disputa hegemônica e ressignificação democrática. In: VAL, Eduardo Manuel; BELLO, Enzo. O pensamento pós e descolonial no novo constitucionalismo latino-americano. Caxias do Sul: Educs, 2014. p. 87-102.

VARGAS, Idón Moisés Chivi. Os caminhos da descolonização na América Latina: os Povos Indígenas e o igualitarismo jurisdicional na Bolívia In: VERDUM, Ricardo. Povos indígenas: Constituições e reformas políticas na América Latina. Brasília: Instituto de Estudos Socioeconômicos, 2009. p. 151-166.

WOLKMER, Antonio Carlos. Pluralismo Jurídico: Fundamentos de uma nova cocultura do Direito. 4. ed. São Paulo: Saraiva, 2015. Disponível em: https://books.google.com.br/books?isbn=8502228366. Acesso em: 10 Abr. 2021.

WOLKMER, Antonio Carlos; AUGUSTIN, Sergio; WOLKMER, Maria de Fátima S. O "Novo" Direito à Água no Constitucionalismo da América Latina. Revista Internacional Interdisciplinar Interthesis, Florianópolis, v. 9, n. 1, jan./jun. 2012.

WOLKMER, Antonio Carlos; FAGUNDES, Lucas Machado. Para um novo paradigma de estado plurinacional na América Latina. Novos Estudos Jurídicos, v. 18, n. 2, p. 329-342, 2013.

TAPIA, Luis. Una reflexión sobre la idea de Estado plurinacional. Osal, v. 8, n. 22, p. 47-63, 2007. 
Para publicar na revista Brasileira de Políticas Públicas, acesse o endereço eletrônico www.rbpp.uniceub.br

Observe as normas de publicação, para facilitar e agilizar o trabalho de edição. 